Marquette University

e-Publications@Marquette

Biomedical Engineering Faculty Research and

Publications

Engineering, College of

$10-1-2014$

\title{
Within-socket Myoelectric Prediction of Continuous Ankle Kinematics for Control of a Powered Transtibial Prosthesis
}

Samuel Farmer

Marquette University, samuel.farmer@marquette.edu

M. Barbara Silver-Thorn

Marquette University, barbara.silver-thorn@marquette.edu

Philip A. Voglewede

Marquette University, philip.voglewede@marquette.edu

Scott A. Beardsley

Marquette University, scott.beardsley@marquette.edu

Accepted version. Journal of Neural Engineering, Vol. 11, No. 5 (October 2014): 056027. DOI. (C) 2014 IOP Publishing Ltd. Used with permission. 


\title{
Within-Socket Myoelectric Prediction of Continuous Ankle Kinematics for Control of a Powered Transtibial Prosthesis
}

\author{
Samuel Farmer \\ Department of Biomedical Engineering, Marquette University, \\ Milwaukee, WI \\ Barbara Silver-Thorn \\ Department of Biomedical Engineering and Department of \\ Mechanical Engineering, Marquette University, \\ Milwaukee, WI \\ Philip Voglewede \\ Department of Mechanical Engineering, Marquette University, \\ Milwaukee, WI \\ Scott A. Beardsley \\ Department of Biomedical Engineering, Marquette University, \\ Milwaukee, WI \\ Clinical and Translational Science Institute, Medical College of \\ Wisconsin, Milwaukee, WI
}

Journal of Neural Engineering, Vol 11, No. 5 (October 2014): pg. 056027. DOI. This article is (C [IOP Publishing and permission has been granted for this version to appear in e-Publications@Marquette. IOP Publishing does not grant permission for this article to be further copied/distributed or hosted elsewhere without the express permission from IOP Publishing. 
NOT THE PUBLISHED VERSION; this is the author's final, peer-reviewed manuscript. The published version may be accessed by following the link in the citation at the bottom of the page.

\section{Abstract}

Objective. Powered robotic prostheses create a need for natural-feeling user interfaces and robust control schemes. Here, we examined the ability of a nonlinear autoregressive model to continuously map the kinematics of a transtibial prosthesis and electromyographic (EMG) activity recorded within socket to the future estimates of the prosthetic ankle angle in three transtibial amputees. Approach. Model performance was examined across subjects during level treadmill ambulation as a function of the size of the EMG sampling window and the temporal 'prediction' interval between the EMG/kinematic input and the model's estimate of future ankle angle to characterize the trade-off between model error, sampling window and prediction interval. Main results. Across subjects, deviations in the estimated ankle angle from the actual movement were robust to variations in the EMG sampling window and increased systematically with prediction interval. For prediction intervals up to $150 \mathrm{~ms}$, the average error in the model estimate of ankle angle across the gait cycle was less than $6^{\circ}$. EMG contributions to the model prediction varied across subjects but were consistently localized to the transitions to/from single to double limb support and captured variations from the typical ankle kinematics during level walking. Significance. The use of an autoregressive modeling approach to continuously predict joint kinematics using natural residual muscle activity provides opportunities for direct (transparent) control of a prosthetic joint by the user. The model's predictive capability could prove particularly useful for overcoming delays in signal processing and actuation of the prosthesis, providing a more biomimetic ankle response.

\section{Introduction}

The interface between humans and robots is an expanding and clinically relevant field. As robotic technology advances, the need for natural-feeling, user-friendly interfaces increases, especially in regards to robotic prostheses and their control mechanisms. Approaches to closed-loop control of active lower limb prostheses have focused on kinetic/kinematic sensing of the prosthesis itself and/or electromyographic (EMG) sensing of muscle activity in the residual or sound limb (Jimenez-Fabian and Verlinden 2012). Control based on kinetic/kinematic sensing within the prosthesis provides high quality and continuous information on the state of the prosthesis. However, adjustments to changes in terrain are generally reactive (introducing delays) and do not readily incorporate information on user intent, posing challenges for seamless everyday control. Surface EMG signals, which precede the corresponding limb kinematics, are more predictive

Journal of Neural Engineering, Vol 11, No. 5 (October 2014): pg. 056027. DOI. This article is @ [IOP Publishing and permission has been granted for this version to appear in e-Publications@Marquette. IOP Publishing does not grant permission for this article to be further copied/distributed or hosted elsewhere without the express permission from IOP Publishing. 
by nature but have lower signal quality than sensors embedded in the prosthesis, posing challenges for robust continuous control.

Continuing improvements in active control of upper extremity prostheses demonstrate that myoelectric signals can be used to provide sequential control of a prosthesis (Englehart and Hudgins 2003, Kuiken et al 2005, Parker et al 2006, Shenoy et al 2008, Fougner et al 2012); see Fougneret al (2012) and Scheme and Englehart (2011) for a review. Studies involving targeted muscle reinnervation (Kuiken et al 2005, 2009, Bueno et al 2011, Akhtar et al 2012, Hebert and Lewicke 2012) suggest that simultaneous multidimensional control is possible. EMG pattern recognition control algorithms in robotic upper extremity prostheses routinely produce classification rates greater than $95 \%$ for multi-dimension joint movement (Khezri and Jahed 2007, Zhou et al 2007, Scheme et al 2013, Wurth and Hargrove 2013). Proportional and feature-driven control based on EMG signals has also been used to provide continuous multi-dimensional control of upper extremity prostheses (Yatsenko et al 2007, Artemiadis and Kyriakopoulos 2010, Jiang et al 2012, 2013, Muceli and Farina 2012, Li et al 2013).

Recent studies have demonstrated the feasibility of using lower extremity EMG signals for active control (Au et al 2008, Delis et al 2009, Hargrove et al 2009, Ha et al 2011, Hargrove et al 2011, 2013, Huang et al 2011, Huang and Ferris 2012, Silver-Thorn et al 2012, Miller et al 2013, Wentink et al 2013, Wentink et al 2014). Myoelectric control in these studies has been largely limited to discrete control modes that require conscious activation of predefined muscle patterns (Au et al 2008, Ha et al 2011, Hargrove et al 2011, Huang et al 2011, Miller et al 2013). EMG classification using linear discriminant analysis (LDA) and support vector machines (SVMs) have been shown to classify walking modes with accuracies up to 97\% (Miller et al 2013). When applied to EMG signals from natively reinnervated residual thigh muscles, LDA pattern recognition has been shown to assist the control of a transfemoral, robotic prosthesis (Hargrove et al 2013).

Conscious proportional myoelectric control has also been shown to provide robust control (Ferris et al 2006, Ferris and Lewis 2009, Huang et al 2011, Dawley et al 2013, Hargrove et al 2013, Wang et al 2013). These systems have demonstrated notable success in

Journal of Neural Engineering, Vol 11, No. 5 (October 2014): pg. 056027. DOI. This article is (C [IOP Publishing and permission has been granted for this version to appear in e-Publications@Marquette. IOP Publishing does not grant permission for this article to be further copied/distributed or hosted elsewhere without the express permission from IOP Publishing. 
facilitating the control of active lower extremity prostheses (Ferris et al 2006, Huang et al 2011, Hargrove et al 2013, Wang et al 2013). However, such systems impose additional layers of processing by the user to determine the appropriate control mode (and corresponding muscle activation pattern) and timing to transition between control modes. A continuous control strategy that takes advantage of the brain's inherent motor planning and prediction capabilities, vis-à-vis the natural muscle activation patterns (Ferris et al 2006, Yatsenko et al 2007, Ferris and Lewis 2009, Jiang et al 2012, Li et al 2013, Wentink et al 2013), could provide truly seamless control capable of adjusting limb dynamics on the fly.

The current study builds on previous work characterizing withinsocket EMG acquired from residual muscles of three transtibial amputees (Silver-Thorn et al 2012). A retrospective analysis of the corresponding EMG and kinematic data was performed here to determine the feasibility of using within socket EMG to provide continuous estimates of future limb state that could be used to control an active transtibial prosthesis. A nonlinear autoregressive model was developed that uses residual limb plantarflexor and doriflexor EMGs, together with the cyclic nature of lower extremity movements, to continuously predict kinematics of the prosthetic ankle. The robustness of the model performance across subjects was quantified and the tradeoff in performance characterized as a function of prediction interval and EMG sampling window. Finally, the timing and extent of EMG contributions to the model predicted kinematics was investigated to identify periods of the gait cycle during which EMG provides discriminable signals for intended gait.

\section{Methods}

EMG and kinematic data acquired previously from transtibial amputees wearing passive prostheses during level treadmill ambulation were used to train and test an autoregressive model to predict ankle angle of the prosthesis. Methods for data acquisition and pre-processing relevant to the current study are outlined below. For additional details, see (Silver-Thorn et al 2012). Written informed consent was obtained from all participants prior to testing in

Journal of Neural Engineering, Vol 11, No. 5 (October 2014): pg. 056027. DOI. This article is @ [IOP Publishing and permission has been granted for this version to appear in e-Publications@Marquette. IOP Publishing does not grant permission for this article to be further copied/distributed or hosted elsewhere without the express permission from IOP Publishing. 
NOT THE PUBLISHED VERSION; this is the author's final, peer-reviewed manuscript. The published version may be accessed by following the link in the citation at the bottom of the page.

accordance with the Institutional Review Board at Marquette University.

\subsection{Data acquisition and analysis}

Plantarflexor and dorsiflexor EMGs were recorded from the residual limbs of three transtibial amputees (button electrodes and pre-amplifier; Liberating Technologies, Holliston, MA) together with kinematic and kinetic data from both the sound and amputated limbs as subjects walked on an instrumented split-belt treadmill (Bertec, Columbus, $\mathrm{OH}$ ). The current prosthesis of each subject included a total surface bearing socket; suspension was via an Alpha locking liner, IceRoss locking liner, and PSI liner with elevated vacuum, respectively for subjects $1-3$. The test prosthesis included a check socket that duplicated the subject's current socket and distal components, inclusive of their prosthetic foot (BioQuest, Axia, Soleus, respectively) (Silver-Thorn et al 2012).

Myosite testing for potential plantar/dorsiflexor sites that demonstrated independent control were identified using a prosthetic myotester (MyoBoy ${ }^{\circledR}$, model \#757M11, Otto Bock, Duderstadt, Germany). The plantarflexor sites were typically on the posterior calf, over the gastrocnemius-soleus; the dorsiflexor sites were on the lateral flare of the remnant anterior tibia, over the anterior tibialis. Button electrodes were then positioned over these sites in a triangular arrangement (two electrodes along longitudinal axis of the muscle belly; a third ground electrode was positioned such that it completed an equilateral triangle; inter-electrode spacing was approximately 1 $\mathrm{cm})$.

EMGs were acquired at two sites from within the prosthetic socket at the interface between the skin of the residual limb and the prosthetic liner. EMG signals were notch filtered at $60 \mathrm{~Hz}$, rectified and then band-pass filtered from 10 to $500 \mathrm{~Hz}$ (zero-phase 2nd order Butterworth) prior to sampling at $1000 \mathrm{~Hz}$. Low frequency envelopes for the EMG signals were obtained by low-pass filtering at $10 \mathrm{~Hz}$ (zerophase 2nd order Butterworth). The resultant 'enveloped' signal was down sampled to $100 \mathrm{~Hz}$ for subsequent analysis.

Journal of Neural Engineering, Vol 11, No. 5 (October 2014): pg. 056027. DOI. This article is @ [IOP Publishing and permission has been granted for this version to appear in e-Publications@Marquette. IOP Publishing does not grant permission for this article to be further copied/distributed or hosted elsewhere without the express permission from IOP Publishing. 
Kinematic data from the sound and amputated limbs were collected using reflective markers placed bilaterally (toe, lateral malleoli, heel, mid-shank, lateral femoral epicondyle, lateral thigh, anterior superior iliac spine) and the sacrum to track the limb position over time as subjects walked on an instrumented treadmill. Marker locations on the prosthetic limb were approximated based on the sound limb locations. Marker locations were sampled at $100 \mathrm{~Hz}$ using a six-camera motion tracking system (Vicon, Oxford, UK), and converted during post-processing to measurements of limb position, knee and ankle angle over time using the Vicon software. Kinetic data from instrumented treadmill were sampled at $1000 \mathrm{~Hz}$ and synchronized to the kinematic and EMG data using the Vicon hardware together with customized Matlab (Mathworks, Natick, MA) scripts.

During the experiment, each subject performed ten walking trials (10 s each) collected sequentially over a 2 min period. Prior to the start of each trial, subjects accelerated to their self-selected walking speed. Data collection began when the subject reached their self-selected pace. Kinematic and kinetic data were processed using Vicon Nexus (v.1.4.116) to obtain lower limb joint angles (hip, knee, and ankle) and ground reaction forces and moments. The ground reaction forces were used to identify gait events, including bilateral heel strike and toe off, which were in turn used to delineate gait cycles for the model analyses.

\subsection{Time series model}

A nonlinear autoregressive neural network with exogenous input (NARX) was developed in Matlab (R12a) to continuously map withinsocket EMG activity to prosthetic ankle angle in the sagittal plane. The model consisted of an input layer containing the windowed low frequency plantar- and dorsiflexor EMG signals recorded from the residual limb and ankle angle fed back from the model output, a hidden layer containing nonlinear units, and a linear output layer containing a single output corresponding to the estimate of future angular position of the prosthetic ankle (figure 1 ). All inputs were passed through separate tapped delay lines that defined the temporal 'prediction' interval between the model inputs and output such that the model output, $y(n)$, at each time point was a given by

Journal of Neural Engineering, Vol 11, No. 5 (October 2014): pg. 056027. DOI. This article is @ [IOP Publishing and permission has been granted for this version to appear in e-Publications@Marquette. IOP Publishing does not grant permission for this article to be further copied/distributed or hosted elsewhere without the express permission from IOP Publishing. 
NOT THE PUBLISHED VERSION; this is the author's final, peer-reviewed manuscript. The published version may be accessed by following the link in the citation at the bottom of the page.

$$
\begin{gathered}
v[n]=f_{1}\left(b_{1}+\sum_{i=1}^{2} \sum_{k=0}^{q} c_{i}[k] x_{i}[n-m-k]\right. \\
\left.-\sum_{k=1}^{q} a[k] y[n-m-k]\right), \\
y[n]=f_{2}\left(w[n] v[n]+b_{2}\right),
\end{gathered}
$$

where $m$ is the number of time steps in the prediction interval $(T=m \Delta t), q$ is the length of the sampling window, $x_{i}(n-m-k)$ is the low-frequency signal envelope of the ith EMG input $m+k$ time steps in the past, $y(n-m-k)$ is the ankle angle $m+k$ time steps in the past, $c_{i}(k)$ and $a(k)$ are the weights within the sampling windows for the EMG inputs and ankle angle respectively, $f_{1}$ is the tansig function, and $f_{2}$ is linear with unit slope. The prediction interval specified the time between the current EMG inputs and estimates of ankle angle and the future estimate of ankle angle provided as the model output. The sampling window specified the number of past inputs/outputs (over time) used by the NARX to form each estimate of ankle angle.

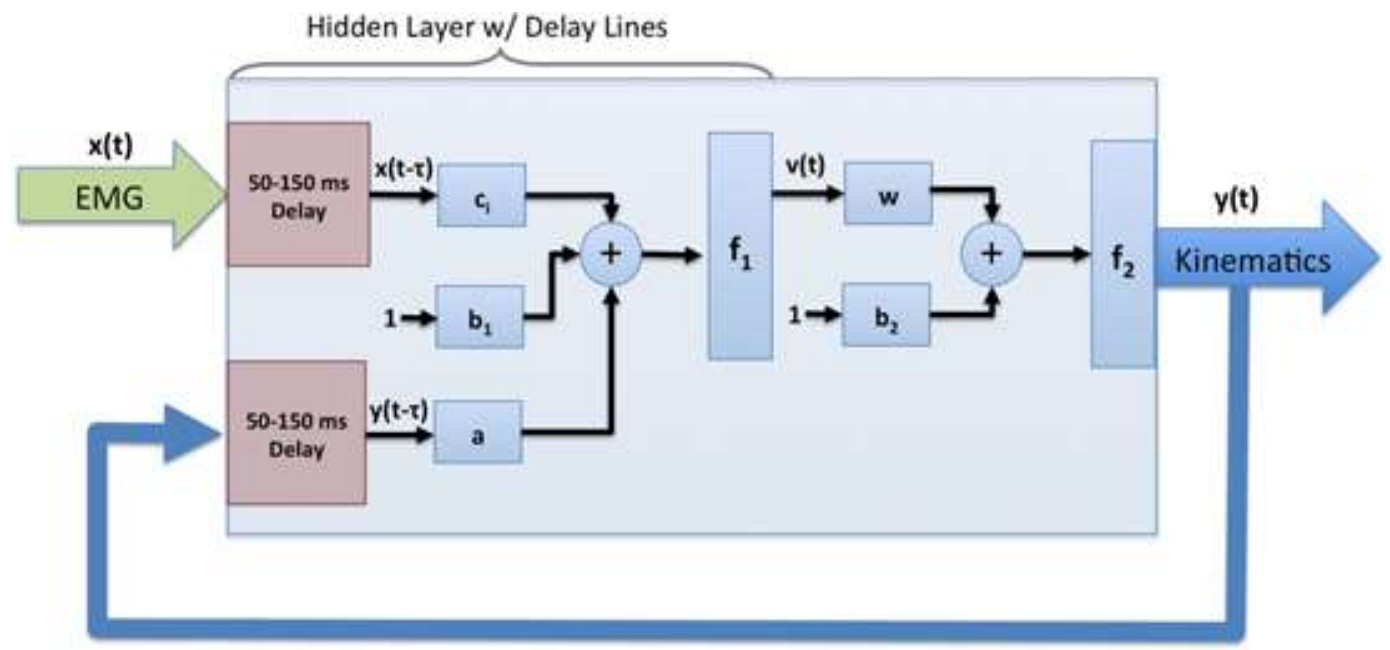

Figure 1. Schematic of the nonlinear autoregressive (NARX) model structure. Windowed EMG activity and previous estimates of ankle angle were weighted and fed via tapped delay lines to a hidden layer comprised of nonlinear units. Outputs from the

Journal of Neural Engineering, Vol 11, No. 5 (October 2014): pg. 056027. DOI. This article is (C) [IOP Publishing and permission has been granted for this version to appear in e-Publications@Marquette. IOP Publishing does not grant permission for this article to be further copied/distributed or hosted elsewhere without the express permission from IOP Publishing. 
NOT THE PUBLISHED VERSION; this is the author's final, peer-reviewed manuscript. The published version may be accessed by following the link in the citation at the bottom of the page.

hidden layer were weighted and linearly combined to provide a continuous estimate of ankle angle over time.

The NARX was optimized for ten hidden units using a supervised learning procedure to minimize the error between the model output and experimentally measured ankle angle. For each subject, the model was trained on eight gait sequences (10 s each), and tested on two separate, randomly selected, gait sequences. For the eight training trials, a leave-one-out cross-validation procedure was used to assess training performance and prevent model over-fitting. Cross-correlation between the experimentally measured and model estimates of ankle angle was used to identify the temporal offset between the time series and bring the datasets into temporal correspondence. Model performance was characterized using the root mean square error (RMSE) between the measured and model estimates of ankle angle. RMSE averaged across five separate model fits was examined as a function of the prediction interval (50-150 ms) and sampling window (10-100 ms) to identify the model structure that provided the best trade-off between prediction interval and mean-square error in the kinematic output. Prediction intervals and sampling windows were sampled at $10 \mathrm{~ms}$ intervals across their respective ranges. The selection of validation trials was randomized for each model fit to account for statistical variations across trials.

\subsection{EMG contribution to predicted kinematics}

The magnitude and timing of the contribution of the EMG inputs to the model estimate of future ankle angle was examined by contrasting the full model (figure 1-optimized with time-varying EMG and time-varying feedback) predictions with those from models with time-varying feedback (i.e., recurrent input), $y(t-T)$, and constant EMG input, $x=\bar{x}$, and models with time-varying EMG input, $x(t)$, and constant feedback, $y=\bar{y}$. Models in which the EMG inputs were constant were optimized using the average EMG signal over time and across training trials. Models in which the feedback was constant were optimized using the average ankle angle over time and across training trials obtained from the full model optimized with time-varying EMG and time-varying feedback. The use of time-averaged signals provided comparable signal power to the full model fit while removing time varying information relevant to gait. In all cases, the NARX models 
were optimized and evaluated using the same training and test trial sequences selected for the full model.

To reduce trial-wise error and facilitate comparisons between model responses, heel strike events were used to parse each $10 \mathrm{~s}$ trial into individual gait cycles. Individual gait cycles were interpolated to unit length (expressed as a percentage of gait cycle) and then averaged to obtain an average estimate of ankle angle as a function of gait cycle. Model predictions of the average ankle angle time series across the gait cycle were subsequently averaged across ten separate model fits and then subtracted from the corresponding measured ankle angle to quantify model error throughout the gait cycle. Differences in model performance across the gait cycle were evaluated for statistical significance using a matched-sample $t$-test at each time point. Temporal intervals containing significant differences were subsequently identified using a three-sample temporal threshold. Variance accounted for (VAF), calculated as one minus the ratio of the error variance divided by the signal variance, was used to quantify the ability of each model to reproduce the ankle angle profile. For the full model, VAF was calculated with respect to the experimentally measured ankle angle. For models with constant EMG or recurrent (feedback) inputs, VAF was calculated with respect to the full model to determine the relative contributions of the model inputs to the overall prediction of ankle angle.

\section{Results}

Figure $\underline{2}$ (a) shows the plantarflexor and dorsiflexor EMGs obtained from subject 2 for one of the two gait trials used to test the fitted model. Subject 2 exhibited considerable co-variation between within-socket recording sites as evidenced by the temporal correspondence between EMG sequences. Figure $\underline{2}$ (b) shows the corresponding ankle angle of the prosthesis measured experimentally together with the ankle angle estimated by the autoregressive model using a 100 ms prediction interval and a 50 ms sampling window for the feedforward (EMG) and feedback (ankle angle) inputs. The model prediction accounted for $96 \%$ of the variance in ankle angle for novel (untrained) gait sequences with an RMSE of $2.6 \pm 0.5^{\circ}$. Similar model performance was obtained for subjects 1 and 3, accounting for $83 \%$

Journal of Neural Engineering, Vol 11, No. 5 (October 2014): pg. 056027. DOI. This article is @ [IOP Publishing and permission has been granted for this version to appear in e-Publications@Marquette. IOP Publishing does not grant permission for this article to be further copied/distributed or hosted elsewhere without the express permission from IOP Publishing. 
and $94 \%$ of the variance in ankle angle with RMSE's of $5.4 \pm 1.2^{\circ}$ and $1.2 \pm 0.2^{\circ}$ on test trials, respectively.

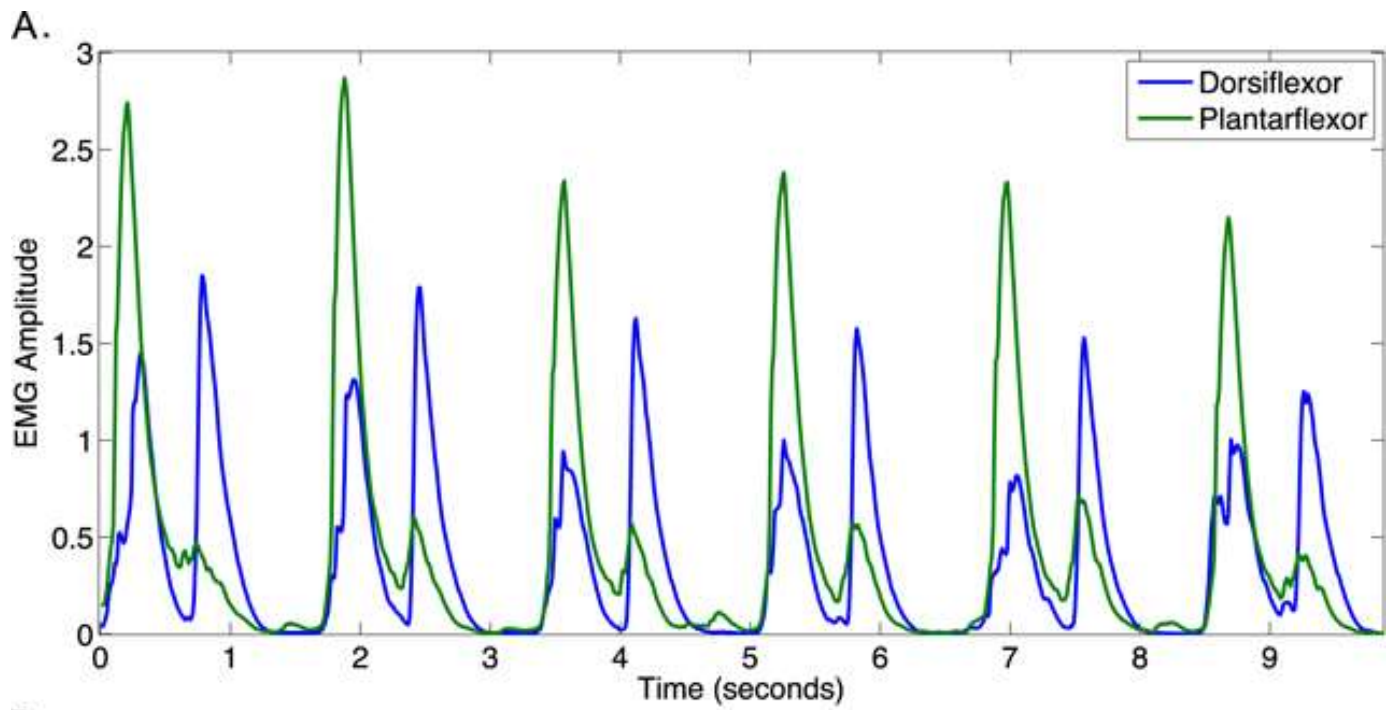

B.
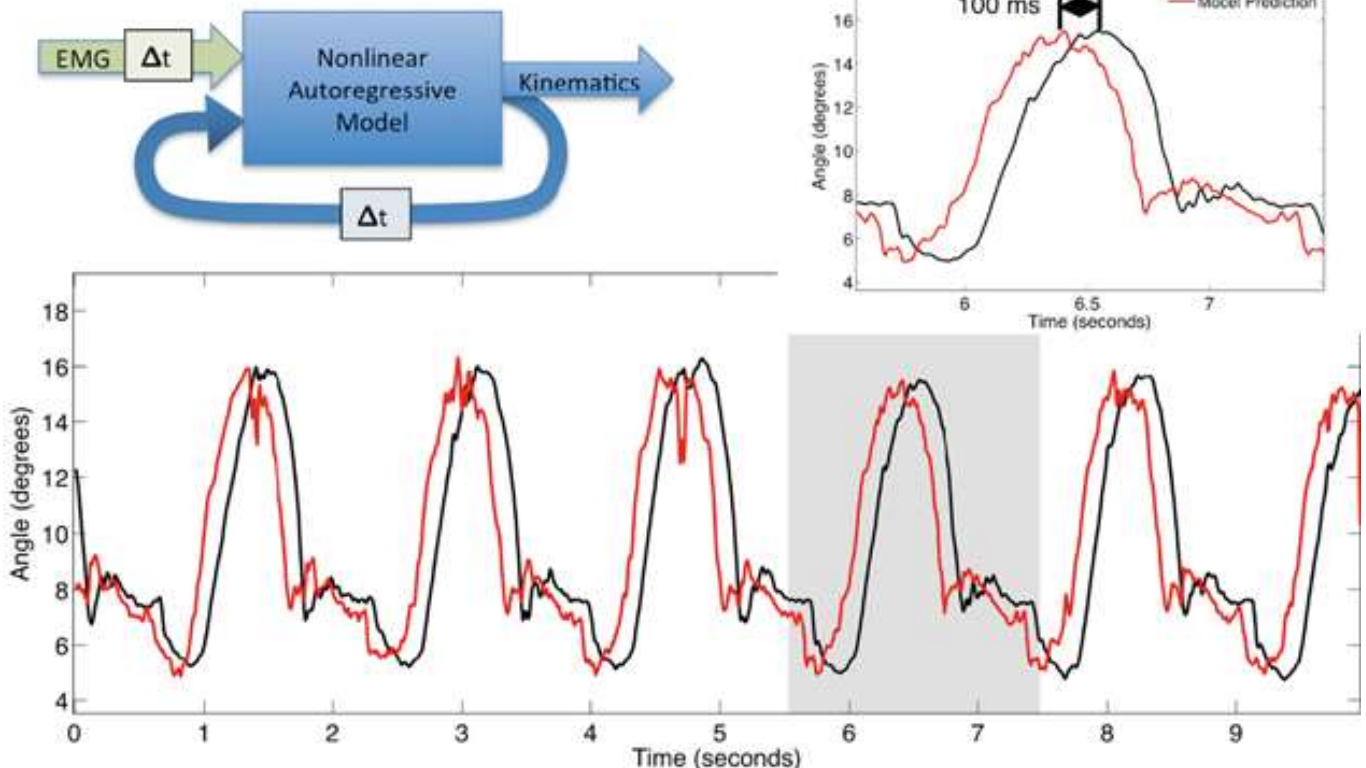

Figure 2. (A) Plantarflexor and dorsiflexor EMG envelope for subject 2 during a leveltreadmill gait sequence used to test model performance. The EMG signals were provided as input to the autoregressive model to predict ankle angle for the gait sequence shown in B. (B) Time course of ankle dorsiflexion angle measured for subject 2 (black) and estimated by the autoregressive model (red) for the EMG sequence in $A$. The model estimate of ankle angle preceded the actual movement by $100 \mathrm{~ms}$ (inset).

Model error in the estimate of future ankle angle was largely unaffected by the size of the sampling window. Error increased

Journal of Neural Engineering, Vol 11, No. 5 (October 2014): pg. 056027. DOI. This article is (C) [IOP Publishing and permission has been granted for this version to appear in e-Publications@Marquette. IOP Publishing does not grant permission for this article to be further copied/distributed or hosted elsewhere without the express permission from IOP Publishing. 
systematically with the size of the prediction interval, with maximum errors saturating for prediction intervals greater than 120 ms (figure 3). RMSE between predicted and measured ankle angle ranged from $0.7^{\circ}$ to $3.4^{\circ}$ across subjects for a 50 ms prediction interval and from $1.3^{\circ}$ to $6.3^{\circ}$ for prediction intervals up to $150 \mathrm{~ms}$. Across the gait cycle, the instantaneous error between the experimentally measured and model estimates of ankle angle varied systematically with the largest errors occurring immediately before and after foot flat and heel rise, respectively (figure $\underline{4}$ ).

A.

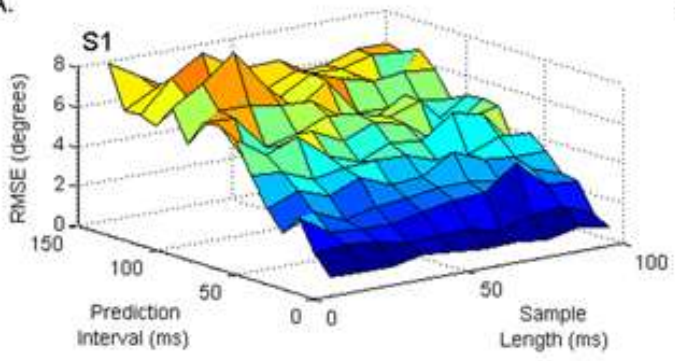

C.

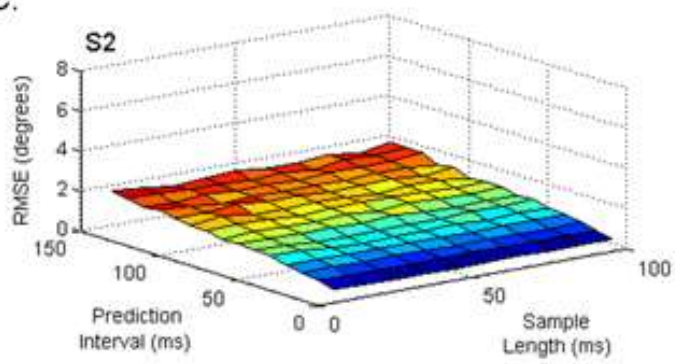

B.

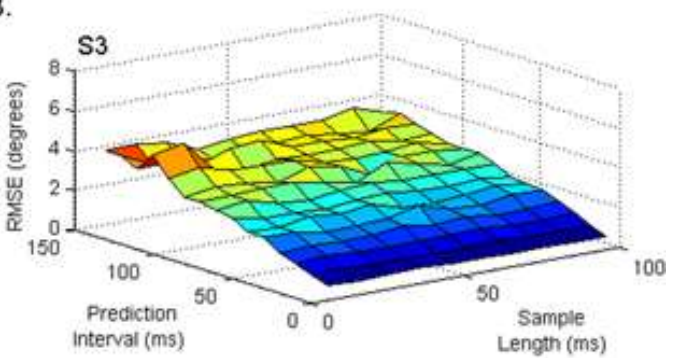

D.

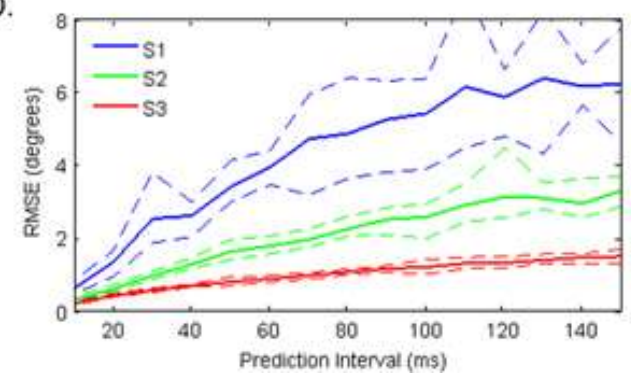

Figure 3. Root mean square error (RMSE) between predicted and actual ankle angle for a novel level treadmill gait sequence as a function of the NARX prediction interval and sampling window. (A)-(C) RMSE for each of the three subjects. Error in ankle angle output by the model increased with prediction interval (saturating after $\sim 120$ $\mathrm{ms}$ ) but did not vary systematically with the width of the sampling window. (D) Average RMSE (solid lines) as a function of prediction interval. RMSE is shown for each subject averaged across the sampling windows shown in (A)-(C). Dotted lines denote the $\mathrm{max} / \mathrm{min}$ range across sample windows.

Journal of Neural Engineering, Vol 11, No. 5 (October 2014): pg. 056027. DOI. This article is @ [IOP Publishing and permission has been granted for this version to appear in e-Publications@Marquette. IOP Publishing does not grant permission for this article to be further copied/distributed or hosted elsewhere without the express permission from IOP Publishing. 
NOT THE PUBLISHED VERSION; this is the author's final, peer-reviewed manuscript. The published version may be accessed by following the link in the citation at the bottom of the page.
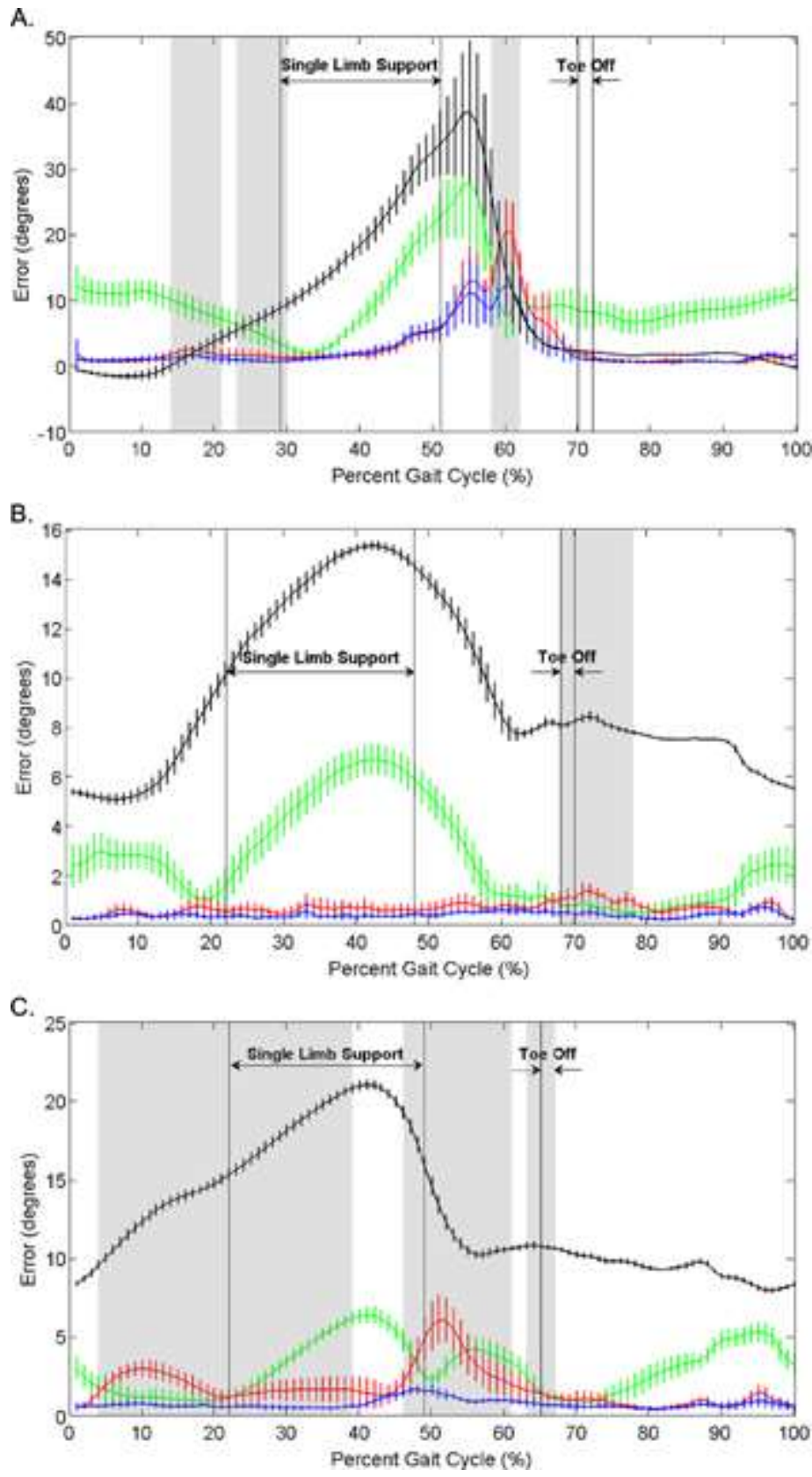

Figure 4. Average contribution of EMG inputs to model prediction error throughout the gait cycle for subjects 1-3 (A)-(C). RMSE averaged across gait cycles is shown for the model response with the time varying EMG input (blue), for the model response with no time varying EMG input (red), i.e., EMG inputs fixed at their average value, and for the model response with no time varying recurrent feedback (green), i.e. recurrent output fixed at its average value. Each subject's ankle angle averaged across gait cycles is shown for comparison (black). Shaded regions indicate statistically significant contributions $(p<0.05)$ of the EMG input to the model prediction. Error bars denote \pm 1 standard deviation.

Journal of Neural Engineering, Vol 11, No. 5 (October 2014): pg. 056027. DOI. This article is @ [IOP Publishing and permission has been granted for this version to appear in e-Publications@Marquette. IOP Publishing does not grant permission for this article to be further copied/distributed or hosted elsewhere without the express permission from IOP Publishing. 
The cyclic nature of gait resulted in a preferential weighting toward the autoregressive feedback such that the prior history of the ankle kinematics accounted for $84 \%, 95 \%$, and $72 \%$ of the model variance across test trials for subjects $1-3$, respectively. EMG inputs contributed to single-/double-limb support transitions and gait-wise variations in ankle angle, accounting for an additional $5-28 \%$ of the model variance. The pattern of EMG contribution across the gait cycle was subject-specific but occurred consistently during transition periods of the gait cycle, from heel strike to foot flat ( $~ 5-20 \%$ gait cycle) and heel rise to toe off ( $\sim 45-65 \%$ gait cycle), (figure 4 ). When the time varying contribution of the EMG input was removed, average errors in predicted ankle angle during the transition periods increased by more than $50 \%(t(18)>2.63, p<0.01)$. Across individual gait cycles, the addition of EMG inputs decreased errors during the transition periods by up to $8.12 \pm 5.13^{\circ}, 0.89 \pm 0.46^{\circ}$, and $4.7 \pm 2.45^{\circ}$ degrees for subjects 1,2 and 3 , respectively.

\section{Discussion}

Current efforts using EMG for closed-loop control of lower limb prostheses have focused primarily on classification of EMG signals to identify discrete classes of movement (Au et al 2008, Delis et al 2009, Hargrove et al 2009, Ha et al 2011, Hargrove et al 2011, Huang et al 2011, Huang and Ferris 2012, Silver-Thorn et al 2012, Hargrove et al 2013, Miller et al 2013, Wentink et al 2013). This emphasis on classification parallels current techniques used in upper limb prosthetic systems to compensate for the uncertainty in mapping a subset of EMG inputs to multiple degrees of freedom and types of movement (Kuiken et al 2005, $\underline{2009}$ Yatsenko et al 2007, Artemiadis and Kyriakopoulos 2010, Bueno French et al 2011, Pulliam Lambrecht et al 2011, Akhtar Hargrove et al 2012, Hebert and Lewicke 2012, Jiang et al 2012, Muceli and Farina 2012, Jiang et al 2013, Li et al 2013). Multi-layer artificial neural networks and SVMs have been used extensively for this purpose in upper extremity prosthetic systems and have been shown to provide accurate discrimination across classes of limb movement, particularly when used in combination with neurofuzzy systems and auto-regressive models (Englehart and Hudgins $\underline{2003}$, Karlik et al 2003, Liu et al 2007, Au et al 2008). In contrast, the autoregressive model presented here takes a continuous approach to

Journal of Neural Engineering, Vol 11, No. 5 (October 2014): pg. 056027. DOI. This article is (C) [IOP Publishing and permission has been granted for this version to appear in e-Publications@Marquette. IOP Publishing does not grant permission for this article to be further copied/distributed or hosted elsewhere without the express permission from IOP Publishing. 
the characterization of limb movement. This approach offers several advantages for closed-loop control that could significantly improve the performance of active lower limb prostheses. The autoregressive modeling approach is particularly well suited to the cyclic patterns encountered during lower limb movement and the reduced degrees-offreedom associated with limb kinematics during gait.

A central benefit of the NARX model lies in its ability to provide a continuous predictive characterization of gait over time as opposed to discrete myoelectric/gait classifications of gait events or modes of ambulation (e.g., overground, stair ascent, etc) (Au et al 2008). The autoregressive model structure takes advantage of the cyclic nature of lower limb movement to predict the repetitive components of movement during gait. For the transtibial amputees examined here, EMG signals were used primarily during transitions to and/or from single limb support where deviations from the cyclic profile had the greatest impact on overall error. Errors in the NARX predictions of ankle angle fell within the range of variability in lower limb kinematics encountered across gait cycles.

The results also suggest that the EMG-specific contribution to ankle angle was dependent on the range of movement (i.e., rotational stiffness) of the prosthesis. The contribution of EMG inputs tended to increase with the range of movement; however, the effect was confounded somewhat by the highly cyclic nature of treadmill walking at a constant speed. As the periodicity of gait increased (e.g., subject 3 ), the recursive nature of the model output reduced the contribution of EMG to the estimated kinematics. This result is consistent with the use of EMG to capture noncyclic variations in amplitude and/or timing associated with movement through a nonhomogeneous environment and/or lower (and more natural) impedance in the prosthesis during ambulation. During movement across real-world terrain, where speed and stride length are more likely to vary, greater contribution of EMG to the predicted kinematics is anticipated. Future tests will examine the robustness of the NARX model to continuously characterize limb kinematics across mobility tasks (e.g., stairs, ramps, and sit-to-stand) and varying speeds with an eye toward implementation in an active prosthesis.

Journal of Neural Engineering, Vol 11, No. 5 (October 2014): pg. 056027. DOI. This article is @ [IOP Publishing and permission has been granted for this version to appear in e-Publications@Marquette. IOP Publishing does not grant permission for this article to be further copied/distributed or hosted elsewhere without the express permission from IOP Publishing. 
Moving forward, the ability to continuously estimate ankle position brings with it additional challenges. Adaptive changes in muscle recruitment patterns, and the corresponding EMG time course, that can occur as subjects adapt to new environments, loads, and changes in gait associated with the use of an active prosthetic system could adversely impact the model's ability to estimate limb state. Periodic retraining of the model could be used to offset quasi-static effects such as adaptation to an active prosthesis. More dynamic effects, such as the changes in body inertia and moments that occur when carrying an object, would require co-adaptation between the model and user (Buttfield et al 2006, Vidaurre et al 2011, Bryan et al 2013, Bensmaia and Miller 2014).

\section{Conclusion}

In this work we have demonstrated that a nonlinear autoregressive model can be used to continuously predict the ankle kinematics of a prosthesis during ambulation using EMG activity recorded within-socket from transtibial amputees. The use of an autoregressive modeling approach to continuously predict joint (i.e., ankle) kinematics using natural residual muscle activity provides opportunities for direct (transparent) control of a prosthetic joint by the user. The use of EMG to predict variations in gait, particularly during transitions, suggests it could be used to identify and seamlessly control joint kinematics across different modes of ambulation (e.g., from overground walking to stair ascent/descent). The model's predictive capability (up to $150 \mathrm{~ms}$ ), could prove particularly useful for overcoming delays in signal processing and actuation of the prosthesis, providing a more biomimetic ankle response. The generalized model structure also makes it well-suited for control of active trans-femoral prostheses as well as active lower-limb orthoses. Future work will evaluate the approach in a larger cohort of amputee subjects across a variety of mobility tasks (e.g., walking, stair ascent/descent) and their transitions to characterize the ability of within socket EMG to continuously estimate limb kinematics using an autoregressive model approach.

Journal of Neural Engineering, Vol 11, No. 5 (October 2014): pg. 056027. DOI. This article is (C) [IOP Publishing and permission has been granted for this version to appear in e-Publications@Marquette. IOP Publishing does not grant permission for this article to be further copied/distributed or hosted elsewhere without the express permission from IOP Publishing. 
NOT THE PUBLISHED VERSION; this is the author's final, peer-reviewed manuscript. The published version may be

accessed by following the link in the citation at the bottom of the page.

\section{References}

Akhtar A, Hargrove L J and Bretl T 2012 Prediction of distal arm joint angles from EMG and shoulder orientation for prosthesis control Conf. Proc. IEEE Eng. Med. Biol. Soc. 2012 4160-3

Artemiadis P K and Kyriakopoulos K J 2010 An EMG-based robot control scheme robust to time-varying EMG signal features IEEE Trans. Inf. Technol. Biomed. 14 582-8

Au S, Berniker M and Herr H 2008 Powered ankle-foot prosthesis to assist level-ground and stair-descent gaits Neural Netw. 21 654-66

Bensmaia S J and Miller L E 2014 Restoring sensorimotor function through intracortical interfaces: progress and looming challenges Nat. Rev. Neurosci. 15 313-25

Bryan M J, Martin S A, Cheung W and Rao R P 2013 Probabilistic coadaptive brain-computer interfacing J. Neural Eng. 10066008

Bueno R A Jr, French B, Cooney D and Neumeister M W 2011 Targeted muscle reinnervation of a muscle-free flap for improved prosthetic control in a shoulder amputee: case report J. Hand Surg. Am. 36 890-3

Buttfield A, Ferrez P W and Millan Jdel R 2006 Towards a robust BCI: error potentials and online learning IEEE Trans. Neural Syst. Rehabil. Eng. 14 164-8

Dawley J A, Fite K B and Fulk G D 2013 EMG control of a bionic knee prosthesis: exploiting muscle co-contractions for improved locomotor function IEEE Int. Conf. Rehabil. Robot 2013 1-6

Delis A L, Carvalho J L, da Rocha A F, Ferreira R U, Rodrigues S S and Borges G A 2009 Estimation of the knee joint angle from surface electromyographic signals for active control of leg prostheses Physiol. Meas. 30 931-46

Englehart K and Hudgins B 2003 A robust, real-time control scheme for multifunction myoelectric control IEEE Trans. Biomed. Eng. $50848-54$

Ferris D P, Gordon K E, Sawicki G S and Peethambaran A 2006 An improved powered ankle-foot orthosis using proportional myoelectric control Gait Posture 23 425-8

Ferris D P and Lewis C L 2009 Robotic lower limb exoskeletons using proportional myoelectric control Conf. Proc. IEEE Eng. Med. Biol. Soc. 2009 2119-24 
Fougner A, Stavdahl O, Kyberd P J, Losier Y G and Parker P A 2012 Control of upper limb prostheses: terminology and proportional myoelectric control-a review IEEE Trans. Neural Syst. Rehabil. Eng. 20 663-77

Ha K H, Varol H A and Goldfarb M 2011 Volitional control of a prosthetic knee using surface electromyography IEEE Trans. Biomed. Eng. 58 144-51

Hargrove L J, Huang $H$, Schultz A E, Lock B A, Lipschutz R and Kuiken T A 2009 Toward the development of a neural interface for lower limb prosthesis control Conf. Proc. IEEE Eng. Med. Biol. Soc. 2009 2111-4

Hargrove L J, Simon A M, Lipschutz R D, Finucane S B and Kuiken T A 2011 Real-time myoelectric control of knee and ankle motions for transfemoral amputees J. Am. Med. Assoc. 305 1542-4 Hargrove L J, Simon A M, Young A J, Lipschutz R D, Finucane S B, Smith D G and Kuiken T A 2013 Robotic leg control with EMG decoding in an amputee with nerve transfers New Engl. J. Med. 369 1237-42

Hebert J S and Lewicke J 2012 Case report of modified Box and Blocks test with motion capture to measure prosthetic function J. Rehabil. Res. Dev. 49 1163-74

Huang H, Zhang F, Hargrove L J, Dou Z, Rogers D R and Englehart K B 2011 Continuous locomotion-mode identification for prosthetic legs based on neuromuscular-mechanical fusion IEEE Trans. Biomed. Eng. 58 2867-75

Huang S and Ferris D P 2012 Muscle activation patterns during walking from transtibial amputees recorded within the residual limbprosthetic interface J. Neuroeng. Rehabil. 955

Jiang N, Muceli S, Graimann B and Farina D 2013 Effect of arm position on the prediction of kinematics from EMG in amputees Med. Biol. Eng. Comput. 51 143-51

Jiang N, Vest-Nielsen J L, Muceli S and Farina D 2012 EMG-based simultaneous and proportional estimation of wrist/hand kinematics in uni-lateral trans-radial amputees $J$. Neuroeng. Rehabil. 942

Jimenez-Fabian R and Verlinden O 2012 Review of control algorithms for robotic ankle systems in lower-limb orthoses, prostheses, and exoskeletons Med. Eng. Phys. 34 397-408 
Karlik B, Tokhi M O and Alci M 2003 A fuzzy clustering neural network architecture for multifunction upper-limb prosthesis IEEE Trans. Biomed. Eng. 50 1255-61

Khezri M and Jahed M 2007 Real-time intelligent pattern recognition algorithm for surface EMG signals Biomed. Eng. Online 645

Kuiken T, Miller L, Lipschutz R, Stubblefield K and Dumanian G 2005 Prosthetic command signals following targeted hyperreinnervation nerve transfer surgery Conf. Proc. IEEE Eng. Med. Biol. Soc. 7 7652-5

Kuiken T A, Li G, Lock B A, Lipschutz R D, Miller L A, Stubblefield K A and Englehart K B 2009 Targeted muscle reinnervation for realtime myoelectric control of multifunction artificial arms J. Am. Med. Assoc. 301 619-28

Li S, Chen X, Sheng X and Zhu X 2013 Preliminary study on proportional and simultaneous estimation of hand posture using surface EMG based on synergy concept Conf. Proc. IEEE Eng. Med. Biol. Soc. 2013 6199-202

Liu Y, Huang $\mathrm{H}$ and Weng C 2007 Recognition of electromyographic signals using cascaded kernel learning machine IEEE/ASME Trans. Mechatronics 12 253-64

Miller J D, Beazer M S and Hahn M E 2013 Myoelectric walking mode classification for transtibial amputees IEEE Trans. Biomed. Eng. $602745-50$

Muceli S and Farina D 2012 Simultaneous and proportional estimation of hand kinematics from EMG during mirrored movements at multiple degrees-of-freedom IEEE Trans. Neural Syst. Rehabil. Eng. 20 371-8

Parker P, Englehart K and Hudgins B 2006 Myoelectric signal processing for control of powered limb prostheses $J$. Electromyogr. Kinesiol. 16 541-8

Pulliam C L, Lambrecht J M and Kirsch R F 2011 Electromyogrambased neural network control of transhumeral prostheses $\mathrm{J}$. Rehabil. Res. Dev. 48 739-54

Scheme E and Englehart K 2011 Electromyogram pattern recognition for control of powered upper-limb prostheses: state of the art and challenges for clinical use J. Rehabil. Res. Dev. 48 643-59

Scheme E J, Hudgins B S and Englehart K B 2013 Confidence-based rejection for improved pattern recognition myoelectric control IEEE Trans. Biomed. Eng. 60 1563-70 
Shenoy P, Miller K J, Crawford B and Rao R N 2008 Online electromyographic control of a robotic prosthesis IEEE Trans. Biomed. Eng. 55 1128-35

Silver-Thorn B, Current T and Kuhse B 2012 Preliminary investigation of residual limb plantarflexion and dorsiflexion muscle activity during treadmill walking for trans-tibial amputees Prosthet. Orthot. Int. 36 435-42

Vidaurre C, Sannelli C, Muller K R and Blankertz B 2011 Co-adaptive calibration to improve BCI efficiency J. Neural. Eng. 8025009

Wang J, Kannape O A and Herr H M 2013 Proportional EMG control of ankle plantar flexion in a powered transtibial prosthesis IEEE Int. Conf. Rehabil. Robot 2013 1-5

Wentink E C, Beijen S I, Hermens H J, Rietman J S and Veltink P H 2013 Intention detection of gait initiation using EMG and kinematic data Gait Posture 37 223-8

Wentink E C, Schut V G, Prinsen E C, Rietman J S and Veltink P H 2014 Detection of the onset of gait initiation using kinematic sensors and EMG in transfemoral amputees Gait Posture 39 391-6

Wurth S M and Hargrove L J 2013 Real-time comparison of conventional direct control and pattern recognition myoelectric control in a two-dimensional Fitts' law style test Conf. Proc. IEEE Eng. Med. Biol. Soc. 2013 3630-3

Yatsenko D, McDonnall D and Guillory K S 2007 Simultaneous, proportional, multi-axis prosthesis control using multichannel surface EMG Conf. Proc. IEEE Eng. Med. Biol. Soc. 2007 6134-7

Zhou P, Lowery M M, Englehart K B, Huang H, Li G, Hargrove L, Dewald J P and Kuiken T A 2007 Decoding a new neural machine interface for control of artificial limbs J. Neurophysiol. 98 2974-82 permission for this article to be further copied/distributed or hosted elsewhere without the express permission from IOP Publishing. 